\title{
VULNERABILITY OF DIFFERENT CLASSES OF LOW-RISE BUILDINGS IN THE 1987 EDGECUMBE, NEW ZEALAND, EARTHQUAKE
}

\author{
David J Dowrick ${ }^{1,2}$, and David A Rhoades ${ }^{1}$
}

\begin{abstract}
SUMMARY
This paper describes an analysis of costs of damage to non-domestic buildings (all low rise) in the $\mathrm{M}_{\mathrm{w}}=$ 6.6 Edgecumbe New Zealand earthquake of 2 March 1987. The damage cost for each building was converted to a damage ratio by dividing it by the replacement value of that building. For the MM7 and MM9 intensity zones, the mean values and statistical distributions of these damage ratios were then found, the lognormal distribution fitting the data well. The data was then divided into subsets according to selected classes of construction, and the vulnerabilities of these classes were measured and compared in terms of their mean damage ratios and the associated $95 \%$ confidence limits. The classes of building examined included classifications by era of design, number of storeys, materials of construction, and building use. Valuable insights into earthquake resistant design and earthquake risk assessment parameters were obtained through the differences observed between classes, notably significant reductions in the vulnerability of buildings associated with improved ductility provisions.
\end{abstract}

\section{INTRODUCTION}

The $\mathrm{M}_{\mathrm{w}}=6.6$ Edgecumbe earthquake of 2 March 1987 was centred in the north-east of New Zealand in the Bay of Plenty. Our present region of interest extends from the centre to the isoseismal for Modified Mercalli intensity VII (MM7), as shown on the isoseismal map used here (Figure 1), as derived by Lowry et al. [1], and used in our previous studies [2-6].

We have previously published studies of the damage in this event, to houses and their contents [2,3] and to non-domestic property [4-6]. In the present paper we are concerned with further studies of the non-domestic buildings. The objectives were to learn more about the effectiveness of past changes in New Zealand earthquake design practices, and to better quantify the vulnerability of different classes of buildings for risk assessment purposes. The opportunity for doing this was good in view of the fact that not only were there a substantial number of non-domestic buildings in the highest intensity zone, MM9, but also that this intensity corresponds to ground shaking slightly higher than the nominal code design level (MM81/2) adopted for the highest seismic hazard zone in New Zealand [7]. Intensity MM9 corresponds to peak ground accelerations (PGA) of 0.4$0.5 \mathrm{~g}$, and a recent model [8] for PGA attenuation in New Zealand indicates that mean PGAs of about $0.4 \mathrm{~g}$ are likely to have occurred within a distance of about $5 \mathrm{~km}$ of the fault rupture (ie within the MM9 zone of this earthquake).

Because of the importance of the isoseismal map to this study, it is noted that the isoseismals (Figure 1) are well constrained by ample intensity observations [1], and a DSIR in-house review of the local intensity values in the MM9 zone subsequently confirmed them. The areas within the inner isoseismals ( $\geq$ MM7) conform well to published and unpublished New Zealand models of intensity attenuation, within the uncertainties imposed by the northern limits of the isoseimals being incomplete (offshore).

While no microzoning study has been done, a general overview of ground conditions in the MM7 and MM9 intensity zones shows that most of the buildings included in this study are located on non-rock sites. In the MM9 zone $80 \%$ or so of the buildings are on deep or flexible soil sites (Category (c) in the New Zealand loadings standard NZS 4203:1992), and the remainder are on intermediate soil sites, category (b). In the MM7 zone the most common soil category is (c) followed by (b), then (a).

In this study non-domestic buildings are defined to mean all buildings other than domestic and farm buildings. Thus we include commercial residential buildings which incorporate hotels, motels, hostels and rest homes providing short term accommodation, and long term rental accommodation of more than one storey. Non-domestic buildings that were governmentowned at the time of the earthquake are also included (e.g. schools, post offices, telecommunications buildings, electricity department buildings).

Institute of Geological \& Nuclear Sciences, Lower Hutt 


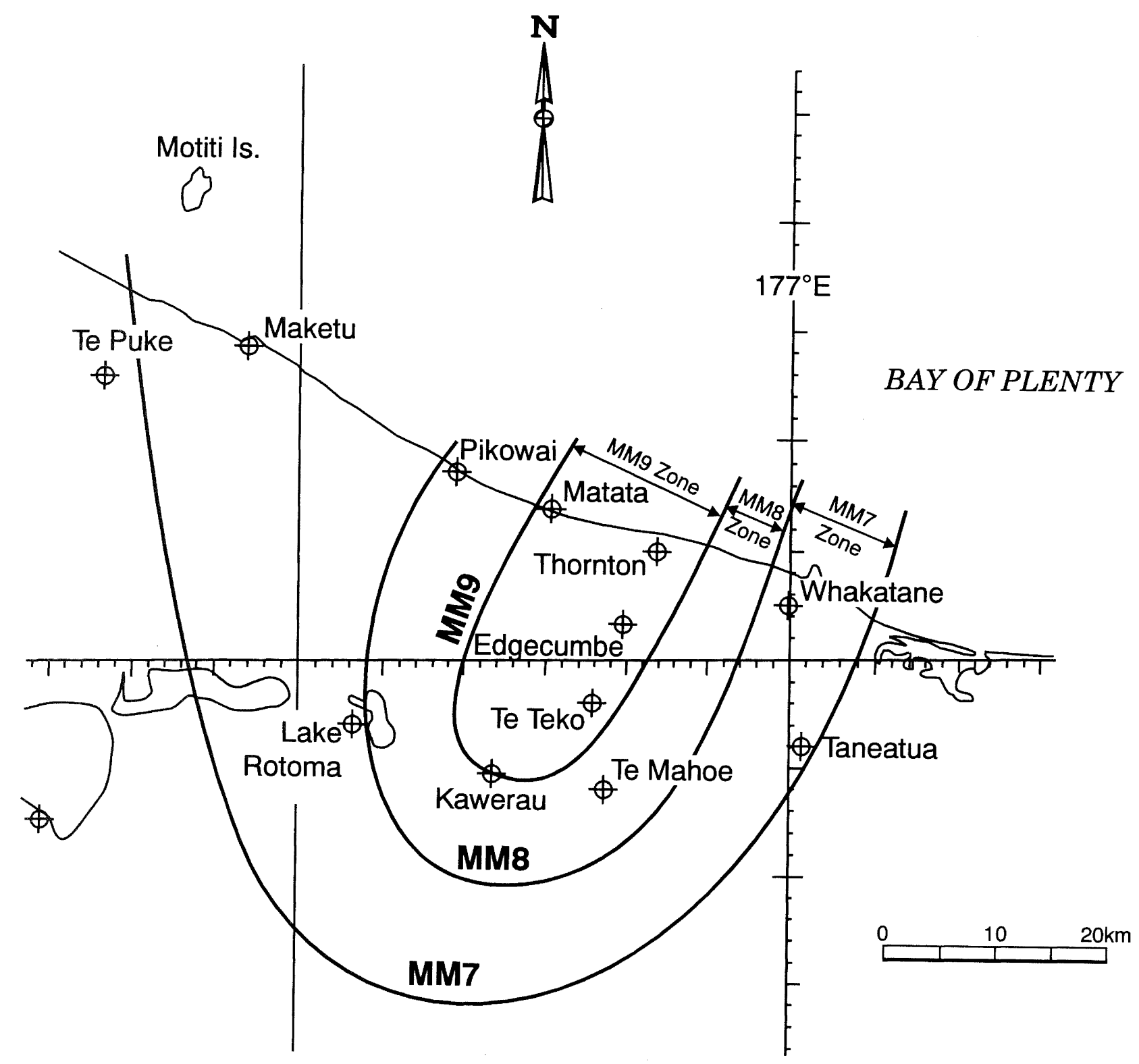

FIGURE 1 Map of inner isoseismals of the 1987 Edgecumbe earthquake (adapted from Ref. 1).

The degree of damage to any class of property at risk is often expressed as a damage ratio, i.e.

$$
D_{r}=\frac{\text { Cost of Damage to Property }}{\text { Value of Property }}
$$

The damage ratio is a function of intensity of shaking and in this paper is related to the MM intensity isoseismals.

As in our related papers [4-6], for the "Value of Property" in equation (1) we use the Replacement Value of each building.

\section{DESCRIPTION OF NON-DOMESTIC BUILDINGS}

So that the replacement values and relative vulnerabilities of the total population of buildings could be evaluated for each intensity zone, it was necessary to find out the number of buildings (damaged and undamaged) in the area of interest, and to obtain a description of the nature of each. To this end, insurance claim data were complemented with data held by Valuation New Zealand and most of the damaged properties were visited. The final database included the following information for all buildings:

$$
\begin{array}{ll}
\text { - } & \text { address (location) } \\
\text { - } & \text { date of construction } \\
& \text { construction materials providing seismic } \\
\text { - } & \text { resistance } \\
\text { - } & \text { reor area } \\
& \text { replacement value }
\end{array}
$$

Let us consider the buildings located in the MM7 and MM9 Intensity zones (Figure 1). An intensity zone is defined as the 
TABLE 1: Statistics of the inner intensity zones

\begin{tabular}{|c|c|c|}
\hline $\begin{array}{c}\text { MM } \\
\text { Intensity } \\
\text { Zone }^{(1)}\end{array}$ & $\begin{array}{c}\text { No of Non-domestic } \\
\text { buildings }^{(2)}\end{array}$ & $\begin{array}{c}\text { Replacement Value } \\
\mathbf{( \$ N Z}^{(3)} \text { million) }\end{array}$ \\
\hline MM 7 Zone & 676 & 195 \\
MM 8 Zone & 110 & 97 \\
MM 9 Zone & 437 & 357 \\
\hline
\end{tabular}

Notes:

(1) For definition of Zones see text and Figure 1.

(2) The number of buildings with RV $>\$ 10,000$ is slightly underestimated.

(3) 1987 dollar values.

area lying between adjacent isoseismals, e.g. the MM7 zone lies between the MM7 and MM8 isoseismals. Note that the MM8 zone is not discussed in detail in this paper, as the number of data are too few for analyses based on them to be statistically robust. As discussed elsewhere [4] the damage ratios for the total ensemble of buildings for MM7 and MM9 Zones are unlikely to include any significant bias due to differences in vulnerability between the populations of buildings in the two zones. We also note that all buildings were low rise, there being very few of over two storeys and none more than six storeys.

The estimated total numbers of buildings and their replacement values for each of the four inner intensity zones are summarised in Table 1. As discussed elsewhere [4], the mean intensities for the buildings in the MM7 and MM9 intensity zones were found to be as follows: $\mathbf{I}_{\mathrm{MM} 7} \approx 7.6$, and $\mathbf{I}_{\mathrm{MM} 9} \approx 9.4$.

The classification of the buildings according to construction material was more difficult than expected, because low-rise buildings in particular are frequently built with a number of materials which interact structurally. Vertical structure may be concrete $(\mathrm{C})$, masonry $(\mathrm{M})$, steel $(\mathrm{S})$ or timber $(\mathrm{T})$, or brick veneer on timber framing $(\mathrm{B})$, or combinations thereof, while floors or roofs are often of a different material from that used in the walls. Each building was inspected and the materials resisting earthquake deformations were noted. The following subsets are the groupings of material classes compared in this paper:

$\begin{array}{ll}\text { Concrete: } & \text { C, CT, CS } \\ \text { Masonry: } & \text { M, MT, MS, CM, BM } \\ \text { Steel: } & \text { S, ST } \\ \text { Timber: } & \text { T, B } \\ \text { Mixed: } & \text { CMT, CMS, MST, CMST }\end{array}$

For the purposes of assessing the influence of design practices on vulnerability, the buildings were initially grouped into four construction date subsets relating to the principal changes in earthquake design and construction practice, as follows:-

\begin{tabular}{|c|c|c|}
\hline (1) & Pre 1935 & $\begin{array}{l}\text { First earthquake design code } \\
\text { introduced } 1935 \text {; }\end{array}$ \\
\hline (2) & $1935-1964$ & $\begin{array}{l}\text { New earthquake loadings code } \\
\text { issued 1965; }\end{array}$ \\
\hline (3) & $1965-1969$ & $\begin{array}{l}\text { Reinforced concrete structures } \\
\text { (improved ductile } \\
\text { procedures for concrete began } \\
\text { informally c. 1970); }\end{array}$ \\
\hline
\end{tabular}

1965-1979

\section{$1970-1987$}

1980-1987

In eras (3) and (4) reinforced concrete structures were defined as buildings where reinforced concrete controlled the earthquake resistance, and included $\mathrm{C}, \mathrm{CS}$ and $\mathrm{CT}$ where $\mathrm{C}$ means entirely concrete, CS means concrete vertical structure with steel roof, and $\mathrm{CT}$ means concrete vertical structure with timber roof. Buildings with significant masonry infill panels were excluded from this category.

While no buildings in the region of interest had been seismically upgraded (retrofitted) at the time of the Edgecumbe earthquake, a number of buildings had of course been built in stages, and in these cases the start and finish dates of construction were included in the data set. In a few cases ( $4 \%$ of MM7 and $8 \%$ of MM9 buildings) the start and finish dates for a given building fall in different date groups. Such buildings were omitted from the design era comparisons.

Expressing the number of buildings of a given material as $\mathrm{N}_{\text {mat }}$ and the total number of buildings in a given design era as $\mathrm{N}$, then the proportion of buildings which are of a given material is $\mathrm{N}_{\text {mat }} / \mathrm{N}$. The proportion of buildings in each of the above five materials subsets, in each of design eras (2), (3) and (4), in each intensity zone MM7 and MM9 are plotted in Figure 2. It is seen that the relative proportions of the numbers of buildings of different materials are quite similar across the three design eras for the MM9 intensity zone, and these are similar to Era (4) of the MM7 zone. Combining the buildings from the two intensity zones, the total numbers in all of the subsets of the five materials and four design eras defined above are: 85 concrete, 410 masonry, 103 steel, 504 timber and 117 mixed materials.

\section{DAMAGE COSTS}

As described elsewhere [4], an attempt was made to find the complete costs of damage to non-domestic property, and to distribute these costs geographically into the respective intensity zones. The subset of this data which relates to the current study is given in Table 2, where it is seen that the damage costs for buildings came to a total of about $\$$ NZ45 million. 
(a) MM7 Design Eras 2 and 3

(b) MM7 Design Eras $2+3$ and 4
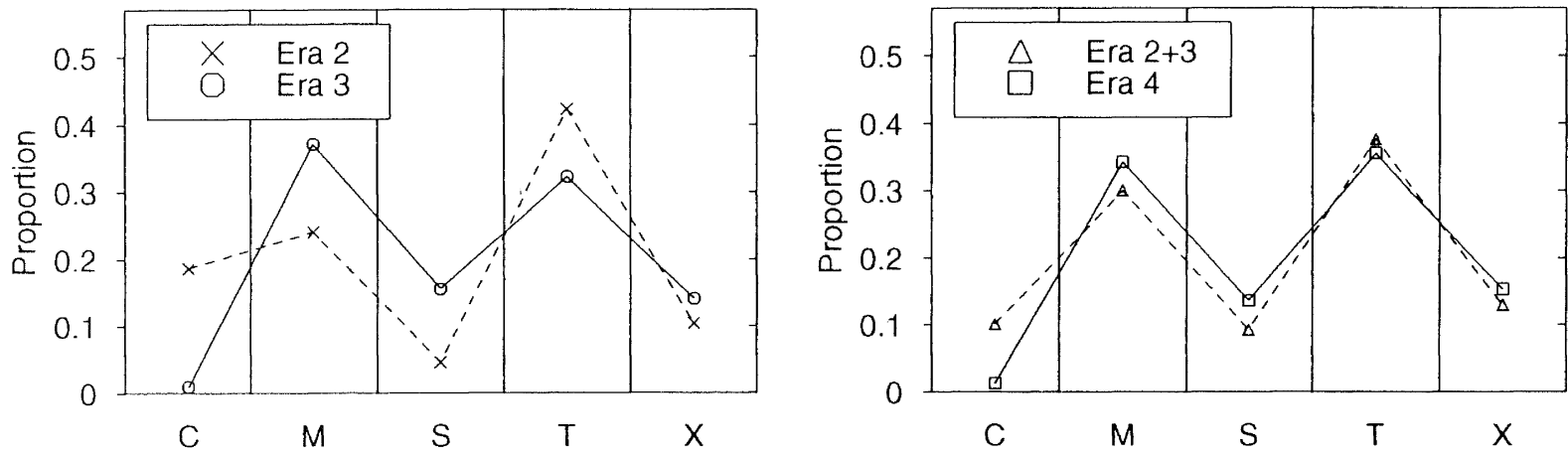

(c) MM9 Design Eras 2 and 3

(d) MM9 Design Eras $2+3$ and 4
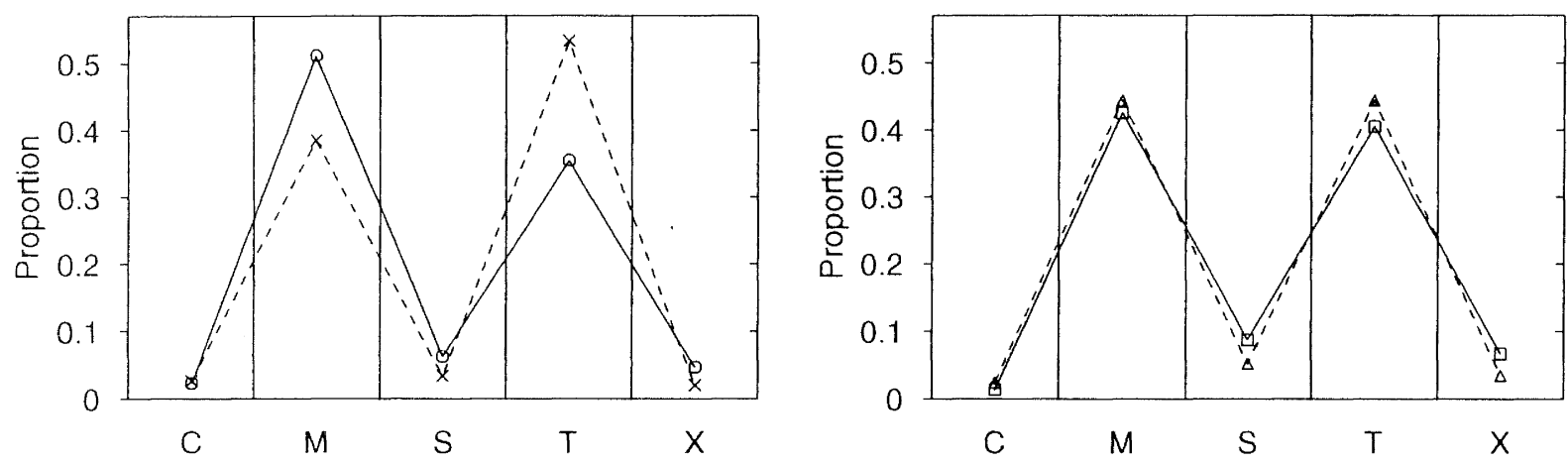

FIGURE 2: $\quad$ Proportion of the total number $N$ of non-domestic buildings of the five materials classes for intensities $M M 7$ and MM9 in the 1987 Edgecumbe earthquake, (a) and (c) comparing design eras (2) and (3), and (b) and (d) comparing design eras (2+3) and (4).

TABLE 2: Non-domestic Buildings in the Edgecumbe Earthquake. Summary of material damage costs (\$NZ 000)

\begin{tabular}{||l|c|c|c|}
\hline \hline \multicolumn{1}{|c|}{ Item Damaged } & $\begin{array}{c}\text { MM7 } \\
\text { Zone }\end{array}$ & $\begin{array}{c}\text { MM8 } \\
\text { Zone }\end{array}$ & $\begin{array}{c}\text { MM9 } \\
\text { Zone }\end{array}$ \\
\hline Buildings & & & \\
1 EQC & 560 & 249 & 26980 \\
2 Private Ins Co* & 84 & 124 & 16418 \\
3 Govt** & 43 & $\mathrm{U}$ & 902 \\
\hline \multicolumn{1}{|c|}{ TOTAL } & 687 & $373+$ & 44300 \\
\hline
\end{tabular}

Notes:

- $\quad$ Losses from Bay Milk factory have been adjusted for analysis purposes.

* $\quad=\quad$ Insurance company losses incomplete, probably not underestimated significantly.

** $\quad=\quad$ Govt means property owned by NZ Government underwritten by itself.

$\mathrm{U}=$ Unknown, but relatively small.

The damage costs at one major site in the MM9 zone, that of the Bay Milk factory, create an untidy aspect to this study. A dispute between the insurers and the insured was decided by a lump sum legal judgement which obscured the true costs of damage for particular buildings and equipment items at this site. The Bay Milk buildings data are very influential in the analysis because the damage levels and replacement values were both high. Because of the above-mentioned difficulties in assessing 
reliable damage ratios for the Bay Milk factory property, the validity of some of the Bay Milk data is questionable. Hence we have presented most results for MM9 zone buildings excluding the Bay Milk data.

\section{DAMAGE RATIOS}

\subsection{Statistical distributions of damage ratios}

The damage ratio for each building was found as a function of Replacement Value, using the specific form of equation (1) as follows:

$$
D_{r}=\frac{\text { Cost of Damage to a Building }}{\text { Replacement Value of Building }}
$$

Other studies by the authors [2-5] of damage in the 1987 Edgecumbe earthquake have shown the shape of the statistical distribution of non-zero damage ratios for several classes of property to be well approximated by a truncated lognormal distribution.

The lognormal distribution has the density function

$$
\begin{aligned}
& f(x)=\frac{1}{\sigma x \sqrt{2 \pi}} \exp \left[-\frac{1}{2}\left(\log _{e} x-\mu\right)^{2} / \sigma^{2}\right], \\
& x>0
\end{aligned}
$$

Here the parameters $\mu$ and $\sigma$ are estimated by the sample mean and standard deviation of the natural logarithm of the damage ratio.

The estimates of the parameters $\mu$ and $\sigma$, found for the various data sets are given in Tables 3 and 4 . Also tabulated are the number of damaged buildings $\mathrm{n}$, and the total population (damaged + undamaged) $\mathrm{N}$. Note that some buildings did not fit into any of the subsets presented, so that the sum of $\mathrm{N}$ for each of the main classes (eras, materials, use) is less than the overall $\mathrm{N}$ given at the top of each table.

Tables 3 and 4 show that $s$ for buildings is greater in the intensity MM9 Zone than the MM7 Zone, for all but one subset. The ratio $\sigma(\mathrm{MM} 9) / \sigma(\mathrm{MM} 7)$ for the various subsets ranges from 0.97 to 4.7, and has the value 1.27 for the whole data set (excluding Bay Milk). Thus the scatter is considerably greater at the higher damage level, possibly because of greater nonlinearity of material behaviour at higher intensity. Curiously, in our study of equipment [5], such a trend was not found, the ratio $\sigma(\mathrm{MM} 9) / \sigma(\mathrm{MM} 7)$ for the various subsets ranging from 0.3 to 2.29 , with the ratio for the whole data set being 1.02 . There is no obvious reason why the buildings and equipment should differ this way.

In this study an appreciable number of buildings in the MM9 zone attained the damage ratio upper limit of one. The lognormal distribution, which is unbounded at the top end, can only be used to describe that part of the damage ratio distribution which is between zero and one. To avoid bias in fitting the truncated lognormal distribution it was necessary to use a trimmed mean in estimating $\mu$, as described in a previous study
[4]. Consistent with earlier findings for other damaged populations [2-5], the data are fitted well by the lognormal distribution, especially for subsets of about 30 data or more. This is demonstrated in Figure 3, where the empirical and fitted lognormal cumulative probability distributions are plotted for $D_{r}$ of buildings of one and two storeys in the MM9 Zone.

Also on Figure 3 are plotted the $95 \%$ confidence limits of the empirical cumulative probability distributions. The confidence limits at a given value of $D_{r}$ are calculated as $p \pm 2[p(1-p) / N]^{1 / 2}$, where $p$ is the proportion of buildings in the class with damage ratio exceeding $D_{r}$. This formula is based on the usual normal approximation to the binomial distribution.

These limits for the one and two storey classes are clearly separated, except for a modest overlap at the high end of the distribution, and show that the difference between one and two storey buildings is easily significant at the $5 \%$ level (as further discussed later).

\subsection{Mean damage ratios}

The mean damage ratio for all buildings in a given MM intensity zone is a useful parameter for various purposes [6], eg. in comparing the earthquake resistance of different classes of property. Considering all $\mathrm{N}$ buildings (damaged and undamaged) in an $\mathrm{MM}$ intensity zone, we give here two principal ways of defining the mean $D_{r}$. Firstly

$\bar{D}_{r}=\frac{\sum_{i=1}^{n}[\text { Cost of damage to building } i]}{\sum_{i=1}^{N}[\text { Value of building } i]}$

where $\mathrm{n}$ is the number of damaged buildings.

Secondly

$D_{r m}=\frac{\sum_{i=1}^{n}\left[D_{r_{i}}\right]}{N}$

In general $D_{r m}$ with its associated confidence limits is a more reliable and useful tool than $\mathbf{D}_{\mathrm{r}}$ [6]. If derived from large, homogeneous populations, $\mathbf{D}_{\mathrm{r}}$ and $\mathrm{D}_{\mathrm{rm}}$ tend to be similar in value, while for more inhomogeneous populations (with large ranges of replacement values and vulnerabilities) $\mathbf{D}_{\mathrm{r}}$ and $\mathrm{D}_{\mathrm{rm}}$ may differ widely. The values of $D_{r}$ and $D_{m}$ for various classes of non-domestic buildings considered in this study are presented in Tables 3 and 4 .

Next we compare the vulnerability of different classes of buildings in terms of mean damage ratio, $D_{m}$ and scatter. 
TABLE 3 Basic statistics of distribution of damage ratios for subsets of non-domestic buildings in the MM9 zone of the Edgecumbe earthquake (excl. Bay Milk, except where noted).

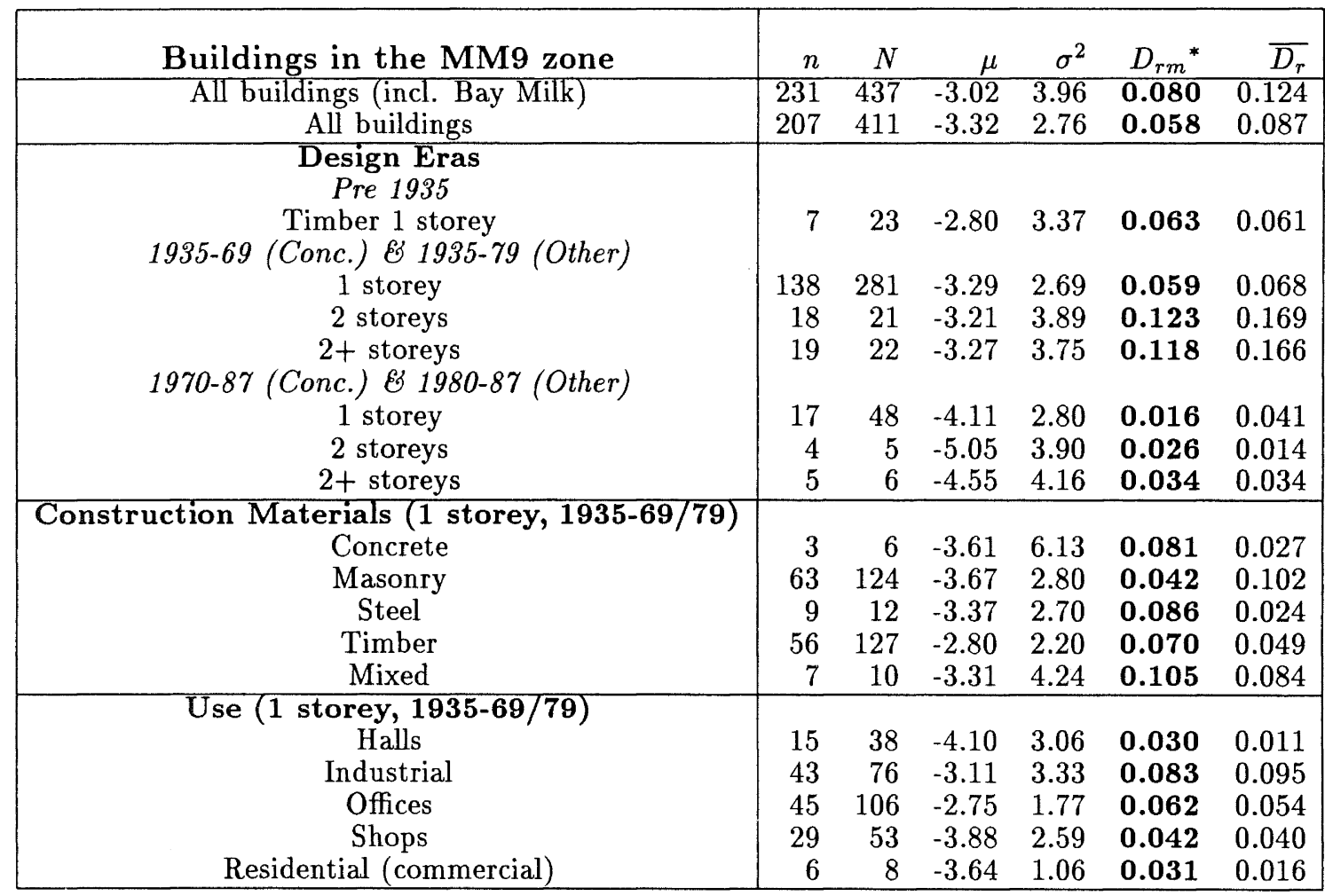

${ }^{*} D_{r m}$ is preferred to $\overline{D_{r}}$ in most circumstances (see text).

\section{Design Era and Materials of Construction}

The mean damage ratios, $\mathrm{D}_{\mathrm{rm}}$, for single storey buildings in the MM9 zone of design eras (2) to (4), as defined in Section 2, are plotted on Figure 4 together with 95 percent confidence intervals on the mean. As reported earlier [6], there is no significant difference between $D_{m}$ for the total populations of buildings of the two earlier eras, which is consistent with the fact that the code changes in 1965 were modest. We note, however, that there were significant differences in the two large materials subsets, i.e., showing an apparent decrease in the vulnerability of the timber and an increase for masonry from era (2) to era (3), suggesting that these subsets were rather small and differently distributed geographically within the intensity zones.

For the most recent era, however, the mean damage level appears to have reduced markedly. Statistically, the difference in $D_{m}$ between the most modern era and the combined data from the two earlier eras is significant at less than the $5 \%$ level. This is the case for each of the subsets: (1) all buildings, (2) one storey buildings and (3) two storey buildings. As well as this reduction in the average damage level, it is seen in Figure 4 that the incidence of heavy damage (ie collapse potential), as measured by the 95 th percentile of $D_{r}$, has also reduced considerably. It is also noted that, although a number of buildings were written off (with $\mathrm{D}_{\mathrm{r}}=1.0$ ), no non-domestic building collapsed due to ground shaking forces. This is in spite of the fact that there were 324 buildings built before 1976 (i.e., built in the so-called "brittle buildings" era before capacity design was required).

The meaning of the results of the above statistical tests is dependent on the composition of the various subsets of buildings. In order to test the effect of design on vulnerability the subsets need to be similar in other respects. For this reason the buildings in these subsets were restricted to those of one storey (the importance of this is demonstrated elsewhere in this paper). In addition it is of interest here to refer back to Figure 2, which shows the mix of construction materials for the various design era subsets. As the proportionate mixture of the different materials is broadly similar in all eras we can have added confidence in the validity of the above statistical differences and similarities.

It can thus be asserted with some confidence that the improvements to New Zealand's design codes introduced in design era (4) have been effective in reducing the vulnerability of single storey buildings to earthquake shaking of intensity MM9. These findings are consistent with the fact that major changes were made in detailing practice for the various structural materials around the beginning of design era (4). The earliest enhancements of the ductility of reinforced concrete started informally in some New Zealand design offices at about 1970, the ductile design of other materials began to improve about 
TABLE 4

Basic statistics of distribution of damage ratios for subsets of non-domestic buildings in the MM7 zone of the Edgecumbe earthquake.

\begin{tabular}{|c|c|c|c|c|c|c|}
\hline Buildings in the MM7 zone & $n$ & $N$ & $\mu$ & $\sigma^{2}$ & $D_{r m}^{*}$ & \\
\hline All buildings & 95 & 676 & -4.81 & 1.71 & 0.0029 & 0.0035 \\
\hline \multicolumn{7}{|l|}{ Design Eras } \\
\hline Timber 1 storey & 3 & 37 & -4.92 & 0.84 & 0.0008 & 0.0005 \\
\hline \multicolumn{7}{|l|}{ 1935-69 (Conc.) \& 1935-79 (Other) } \\
\hline 1 storey & 48 & 426 & -4.72 & 1.40 & 0.0022 & 0.0035 \\
\hline 2 storeys & 17 & 51 & -4.84 & 2.82 & 0.0072 & 0.0070 \\
\hline $2+$ storeys & 18 & 57 & -4.85 & 2.66 & 0.0066 & 0.0044 \\
\hline \multicolumn{7}{|l|}{ 1970-87 (Conc.) \&3 1980-87 (Other) } \\
\hline 1 storey & 8 & 83 & -4.54 & 0.51 & 0.0013 & 0.0024 \\
\hline 2 storeys & 3 & 8 & -4.90 & 4.48 & 0.0088 & 0.0073 \\
\hline $2+$ storeys & 5 & 10 & -4.74 & 3.57 & 0.0128 & 0.0044 \\
\hline \multicolumn{7}{|l|}{ Construction Materials (1 storey, $1935-69 / 79)$} \\
\hline Concrete & 5 & 47 & -5.34 & 1.20 & 0.0008 & 0.0010 \\
\hline Masonry & 27 & 139 & -4.62 & 1.48 & 0.0045 & 0.0092 \\
\hline Steel & 3 & 43 & -5.79 & 0.58 & 0.0003 & 0.0001 \\
\hline Timber & 7 & 174 & -4.15 & 0.10 & 0.0010 & 0.0011 \\
\hline Mixed & 11 & 60 & -4.55 & 1.35 & 0.0035 & 0.0054 \\
\hline \multicolumn{7}{|l|}{ Use (1 storey, $1935-69 / 79)$} \\
\hline Halls & 7 & 49 & -4.22 & 2.45 & 0.0048 & 0.0065 \\
\hline Industrial & 7 & 124 & -5.31 & 1.03 & 0.0004 & 0.0002 \\
\hline Offices & 5 & 133 & -5.42 & 1.89 & 0.0004 & 0.0008 \\
\hline Shops & 17 & 92 & -4.54 & 1.55 & 0.0050 & 0.0104 \\
\hline Residential (commercial) & 12 & 28 & -4.64 & 0.46 & 0.0049 & 0.0050 \\
\hline
\end{tabular}

${ }^{*} D_{r m}$ is preferred to $\overline{D_{r}}$ in most circumstances (see text).

1980, and the earthquake loadings code NZS4203 introduced the anti-collapse principle of capacity design in 1976.

Because of the above finding that there was no significant difference between $\mathrm{D}_{\mathrm{m}}$ for the total population of buildings of Design Eras (2) and (3), the data from these two eras was merged, as shown by the statistics given in Tables 3 and 4 . This has the benefit of creating larger subsets of buildings in the Materials and Use classes, enabling more robust statistical inferences to be made.

As seen in Figure 2 and Tables 3 and 4, the most numerous subsets according to Construction Materials classes are for Masonry and Timber buildings. The sizes of these subsets were large enough to suggest that statistical comparisons of the design eras might be extended from the all-inclusive subsets considered in Figure 4 to these two individual materials.

The effects of design era on the vulnerabilities of timber and masonry one storey buildings are shown in Figure 5 in terms of $\mathrm{D}_{\mathrm{rm}}$ and its associated $95 \%$ confidence limits, as functions of intensity. At intensity MM7 no significant differences were found between any of the timber subsets (Figure 5(a)), or either of the masonry subsets (Figure 5(c)). This is likely to occur because building damage at MM7 is mostly of a non-structural nature. At intensity MM9, for timber buildings it was found that there is a significant difference at the 0.01 level between the $D_{r m}$ values for both the pre-1935 and the 1935-79 eras compared with
1980-87 (Figure 5(b), $\mathrm{D}_{\mathrm{rm}}$ for the latest era being lower. This is consistent with the findings in relation to Figure 4.

Also for timber buildings at intensity MM9, no statistically significant difference is apparent between the pre-1935 (precode) and 1935-79 eras (Figure 5(b)). This finding is thought to reflect, at least partly, the inherent good earthquake performance of even pre-code New Zealand timber construction, which is also exemplified by the low damage levels for pre-code timber houses in Napier in the 1931 Hawke's Bay earthquake, as quantified in considerable detail by Dowrick et al. [9]

For masonry buildings at intensity MM9, while $\mathrm{D}_{\mathrm{m}}$ for the latest design era (1980-87) is only half that of the previous design era (Figure $5(\mathrm{~d})$ ), the difference is not statistically significant. This occurs largely because of the relatively large scatter in the small $(\mathrm{N}=15)$ 1980-87 subset.

Next, comparisons are made of the relative vulnerabilities of different construction materials. For this purpose, first we compared the vulnerabilities of the five materials classes defined above (Section 2), as shown in Figure 6 in terms of $D_{m}$ and its associated $95 \%$ confidence limits, for the MM9 zone, and (as this is the only era with sufficient data) restricted to one storey buildings from the era 1935-1969/79. As discussed above three of these subsets have small populations, with correspondingly large confidence limits seen in Figure 6, so that the comparisons 
can best be made between only the two largest subsets, timber and masonry. Direct comparisons are shown between timber and masonry one storey buildings in Figure 7, where the data for them are plotted for both intensities MM7 and MM9, and for two different design eras. For the 1935-79 era, (Figure 7(a)) timber has a significantly smaller $\mathrm{D}_{\mathrm{rm}}$ than masonry at MM7 at the 0.01 level, and a significantly larger $\mathrm{D}_{\mathrm{m}}$ at $\mathrm{MM} 9$ at the 0.05 level.

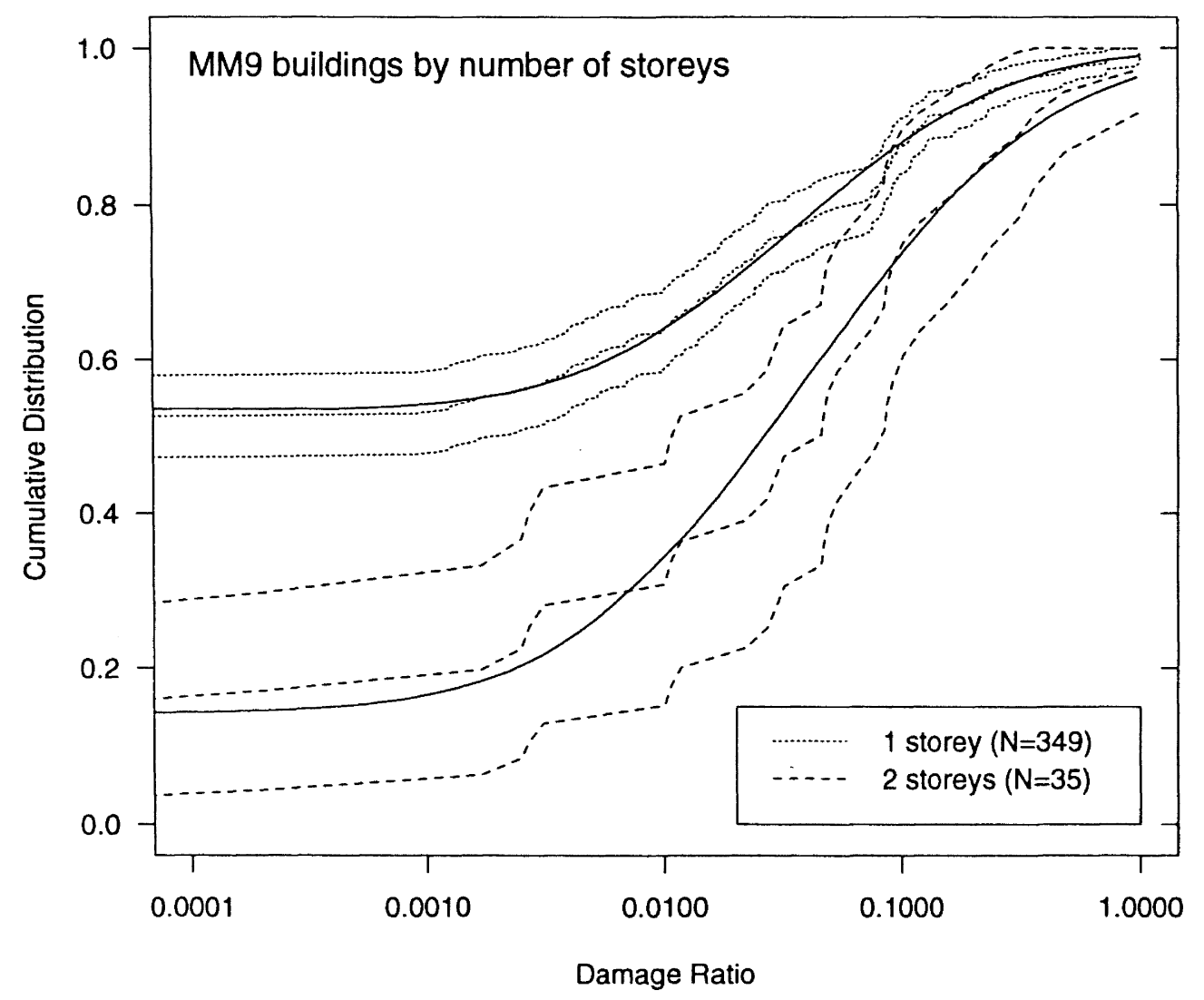

FIGURE 3: $\quad$ Empirical and fitted lognormal cumulative probability distributions for 1935+ non-domestic buildings of one and two storeys in the MM9 intensity zone in the 1987 Edgecumbe earthquake. The 95\% confidence limits of the empirical distributions are also plotted.

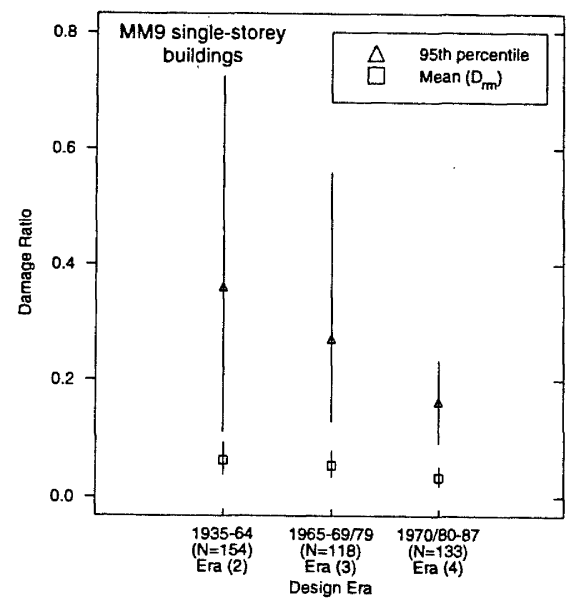

FIGURE 4: $\quad D_{r m}$ and the 95th percentile of $D_{r}$ for non-domestic buildings of three design eras in the intensity MM9 zone of the 1987 Edgecumbe earthquake. The uncertainty limits are the $2.5 \%$ and $97.5 \%$ quantiles of the distributions determined by resampling. 


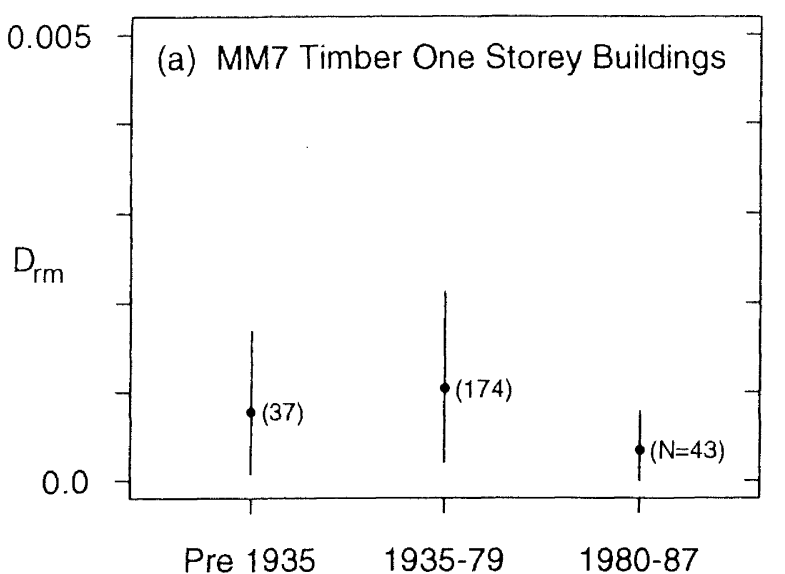

Design era

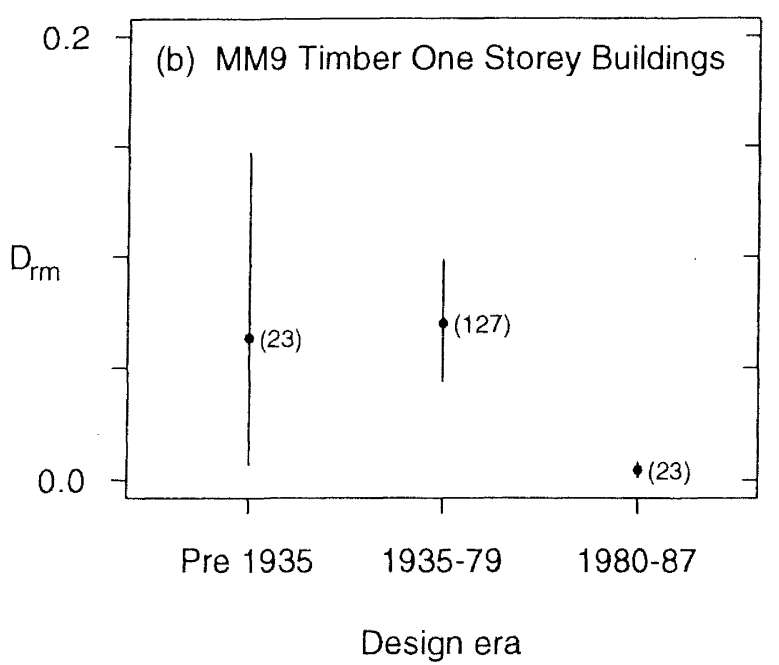

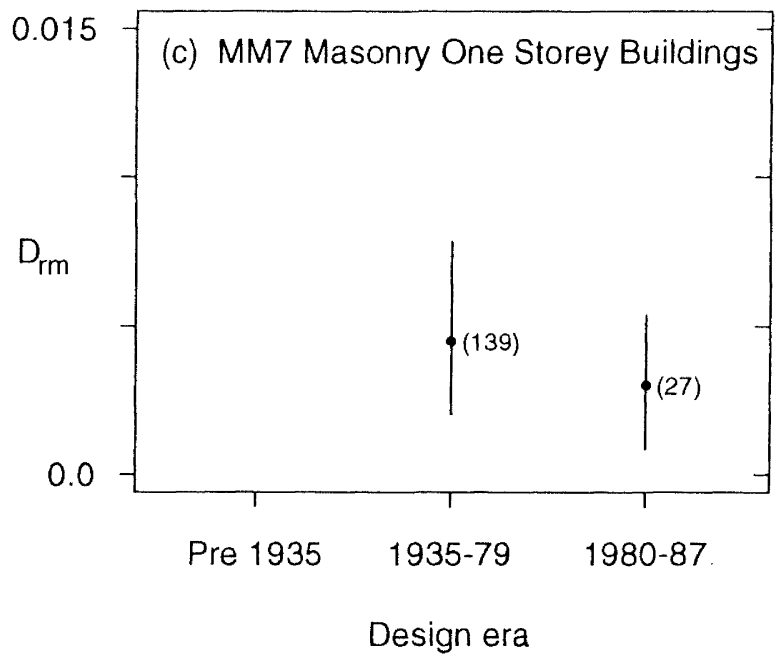

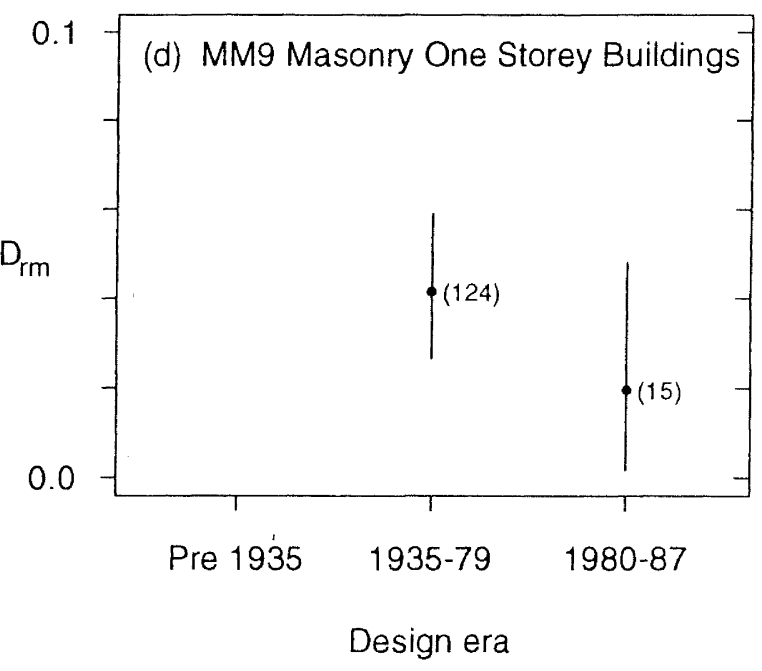

FIGURE 5: $\quad D_{r m}$ and its $95 \%$ confidence limits for one storey timber and masonry non-domestic buildings from different design eras, for intensities MM7 and MM9 in the 1987 Edgecumbe earthquake. (Beware of the different vertical scales of Figures $5(a)-(d))$.

MM9 zone single storey buildings $1935-69 / 79$

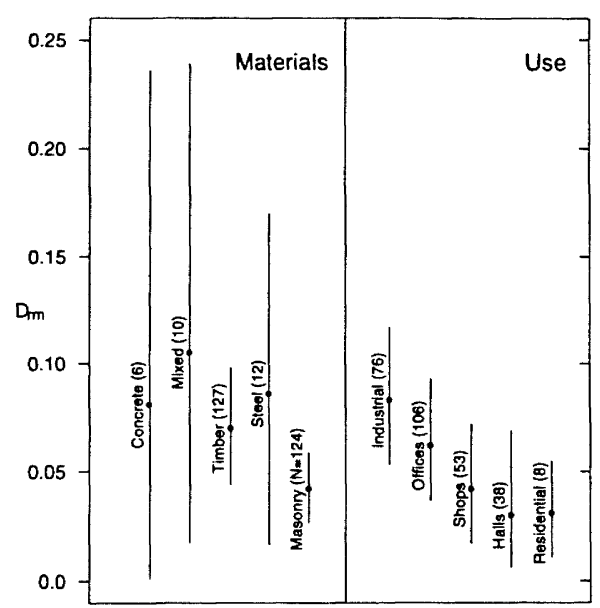

FIGURE 6: $\quad D_{r m}$ and its $95 \%$ confidence limits for one storey non-domestic buildings of different materials and use classes, from design era 1935-1969/79, for intensity MM9 in the 1987 Edgecumbe earthquake. 

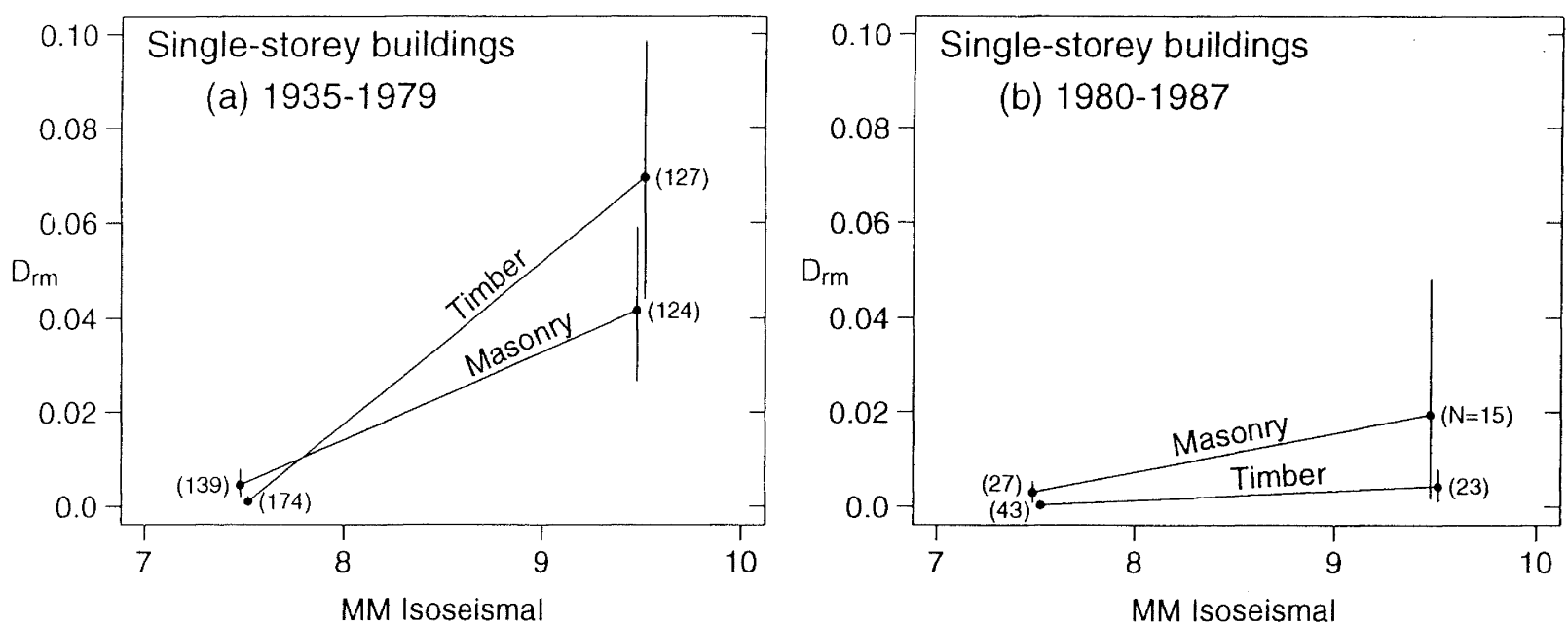

FIGURE 7: $\quad D_{r m}$ and its $95 \%$ confidence limits for one storey non-domestic buildings of timber and masonry from design eras 1935-1979 and 1980-1987 in the 1987 Edgecumbe earthquake.

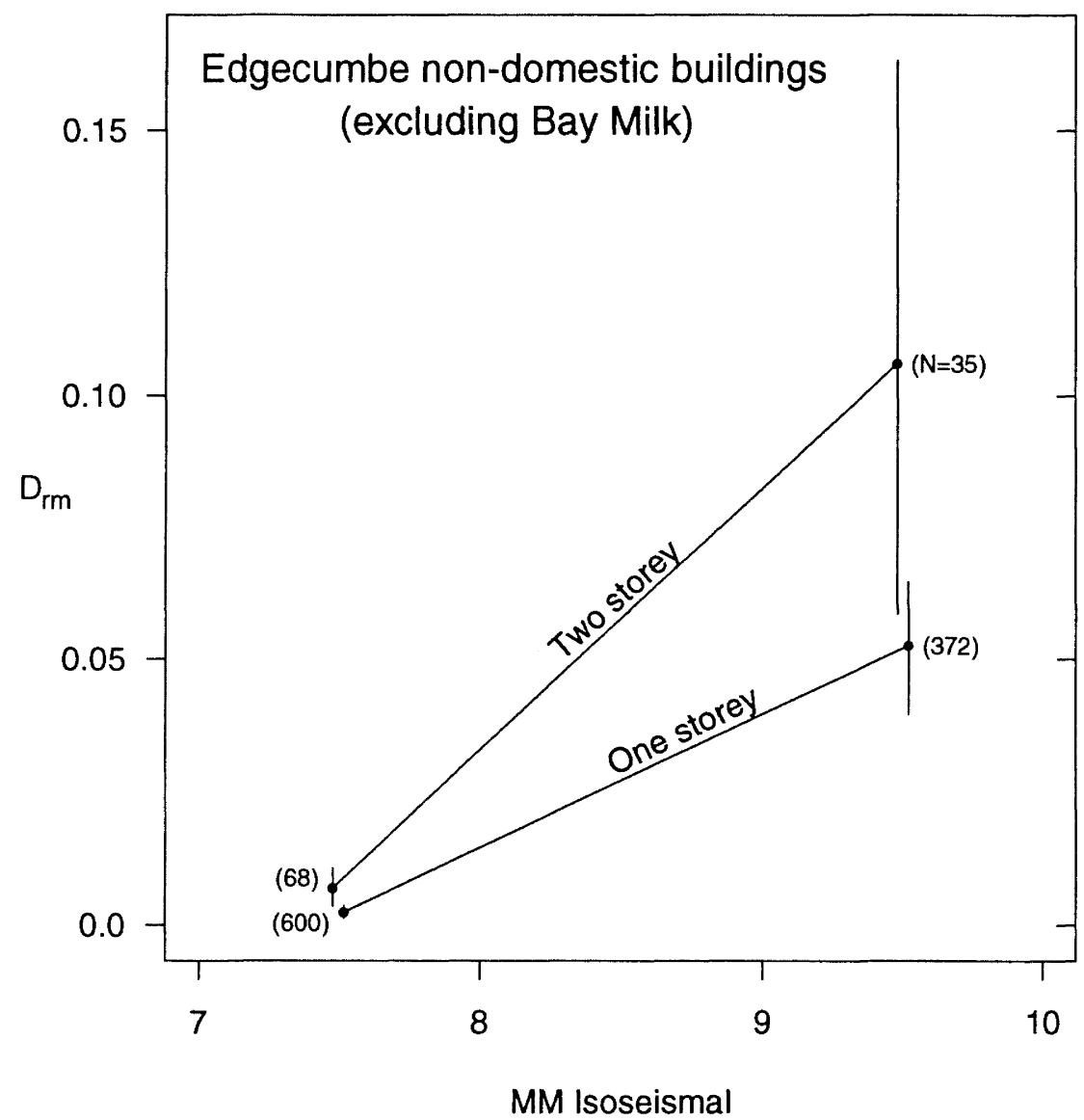

FIGURE 8: $\quad D_{r m}$ and its $95 \%$ confidence limits for one and two storey non-domestic buildings (all materials), for intensities MM7 and MM9 in the 1987 Edgecumbe earthquake. (Plots to linear and logarithmic horizontal scales).

This implies a greater increase in nonlinearity (and hence damage) over the intensity range MM7 to MM9 for timber than for masonry buildings from this design era. This result also appears to reflect the good protection afforded by stiff masonry walls (even in the form of unreinforced concrete block infill) in the population of masonry buildings (as defined in Section 2) at intensity MM9 in this earthquake. We note that MM9 corresponds to ground shaking slightly stronger than the nominal design level for the highest seismic zone of the New Zealand loadings code [7].

This good performance (attributable to structural walls) of postcode masonry buildings at intensity MM9 is echoed by the surprisingly good performance of pre-code low-rise (up to 3- 
storeys) reinforced concrete buildings in Hastings and Napier, at the centre of the magnitude 7.81931 Hawke's Bay earthquake [10]. Only one of these buildings collapsed (i.e. the $3 \frac{1}{2}$ storey Nurses' Home, which had a weak bottom storey).

For the $1980-87$ era (Figure 7(b)), timber has a significantly smaller $D_{\mathrm{m}}$ than masonry at MM7 at the 0.01 level, while at intensity MM9 there is no significant difference. This latter result is a function of the small MM9 masonry subset $(\mathrm{N}=15)$.

\section{Building Use}

Comparison are now made of the relative vulnerabilities of buildings of different use, as defined in Section 2. $D_{\mathrm{m}}$ and its associated $95 \%$ confidence limits are plotted in Figure 6 for the five use classes in the MM9 zone, restricted to one storey buildings from the era 1935-1969/79 (this is the only era for which the data were sufficient). Comparisons of $D_{m}$ for the use classes found that industrial buildings are significantly different from (i.e. more vulnerable than) shops, halls and commercial residential buildings at the $0.05,0.05$ and 0.01 levels respectively. This may occur because industrial buildings are much less likely to gain their earthquake resistance from structural walls than buildings of the other three uses.

\section{Number of Storeys}

Finally the vulnerabilities of buildings of one and two storeys are compared for all buildings in the intensity MM7 and MM9 zones, regardless of age. $D_{r m}$ and its associated $95 \%$ confidence limits for these subsets are plotted on Figure 8. It can be seen that at both MM7 and MM9, $\mathrm{D}_{\mathrm{rm}}$ for two storey buildings is substantially greater than for one storey buildings. Although the number of two storey buildings in the MM9 zone is quite small and the $95 \%$ confidence limits for their $D_{\mathrm{rm}}$ are correspondingly large, $D_{\mathrm{rm}}$ for one and two storey buildings are different at the 0.01 and 0.05 levels at MM7 and MM9 respectively. The influence, if any, of soil conditions, on this finding is not known. However, as noted in the Introduction, the buildings considered tend to be on flexible rather than stiff sites.

Whereas the value of $\mathrm{D}_{\mathrm{m}}$ for one storey buildings is quite robust, it can be seen by the wide confidence limits for two storey buildings (Figure 8 ) that their $\mathrm{D}_{\mathrm{rm}}$ is not well constrained. Hence, while it is evident that two storey buildings are more vulnerable than one storey buildings, the ratio between their respective vulnerabilities is uncertain.

\subsection{Damage ratio as a function of replacement value}

The possibility that damage varies with building size was briefly examined. As shown in Figure 9, the damage ratios for individual buildings of design eras (2) and (3) in the intensity MM9 zone, are plotted against their replacement values (a) for all buildings (b) for timber buildings and (c) for masonry buildings.

The Replacement Values are plotted on both normal and logarithmic scales in an attempt to reveal any trends in the data, but $D_{r}$ and Replacement Value appear to be unrelated, apart from a tendency for the highest damage ratios to occur for the low value properties. This can be compared to the case of timber houses in Napier in the 1931 Hawke's Bay earthquake [9], where a robust smooth trend was fitted which showed that the mean damage ratio was weakly related to house size, as shown here in
Figure 10, again with the highest damage ratios for low value properties. The greater consistency in the trend for single storey timber houses is thought to result from the fact that the houses were much more homogeneous structurally than the nondomestic buildings.

\section{PROPORTION OF BUILDINGS DAMAGED}

The percentage of masonry and timber buildings damaged in the intensity MM7 and MM9 zones for two design eras, 1935-79 and 1980-87, are plotted on Figure 11 together with their $95 \%$ confidence intervals. The actual percentages damaged are seen to be consistently larger for masonry than for timber buildings. At MM7 in the 1935-79 design era the difference between masonry and timber is significantly different at the 0.01 level, but in none of the other three cases is the difference between masonry and timber significant. In the 1935-79 MM9 case this occurs despite the comparatively large numbers of buildings involved, because the percentages damaged for the two classes are quite similar ( $43 \%$ for timber and $50 \%$ for masonry).

Next we compare the effect of the two design eras, on a given materials class. First, at intensity MM7 $19.4 \%$ of masonry buildings from the 1935-79 era were damaged, compared to $18.5 \%$ from the $1980-87$ era, while for timber buildings the corresponding values were 4.0 and $4.7 \%$. As might be expected the differences between the two eras were not statistically significant. This finding is similar to that for $\mathrm{D}_{\mathrm{m}}$ at intensity MM7, as discussed above in relation to Figure 7.

At intensity MM9, 50.8\% of masonry buildings from the 1935 79 era were damaged, but only $33.3 \%$ from the $1980-87$ era. The fact that this large difference is not statistically significant is consistent with the similar comparison for $D_{m}$ for masonry from these two eras, as discussed above in relation to Figure 7. Again at intensity MM9, $44.1 \%$ of timber buildings from the 1935-79 era were damaged, but only $26.1 \%$ from the $1980-87$ era. While this large difference is again not statistically significant, in the corresponding comparison in terms of $\mathrm{D}_{\mathrm{rm}}$ (Figure 7) the difference was statistically significant at the 0.01 level.

As is apparent from a comparison of Figures 7 and 11, and from our studies of other classes of property $[2-6,8]$, that the percentage of property items damaged generally increases with increasing $\mathrm{D}_{\mathrm{rm}}$ across a wide range of property classes.

\section{CONCLUSIONS}

Despite some limitations imposed by the small populations of some of the data subsets, some insights which are valuable for design and risk assessment purposes have been gained into the earthquake vulnerability of a range of classes of low-rise nondomestic buildings. The following conclusions have been drawn:

1. The damage ratios in the range of $0<\mathrm{D}_{\mathrm{r}} \leq 1$ for the various classes of buildings studied here (and in our previous studies) were found to fit to the truncated lognormal distribution, particularly for the larger subsets of about 30 buildings or more. 

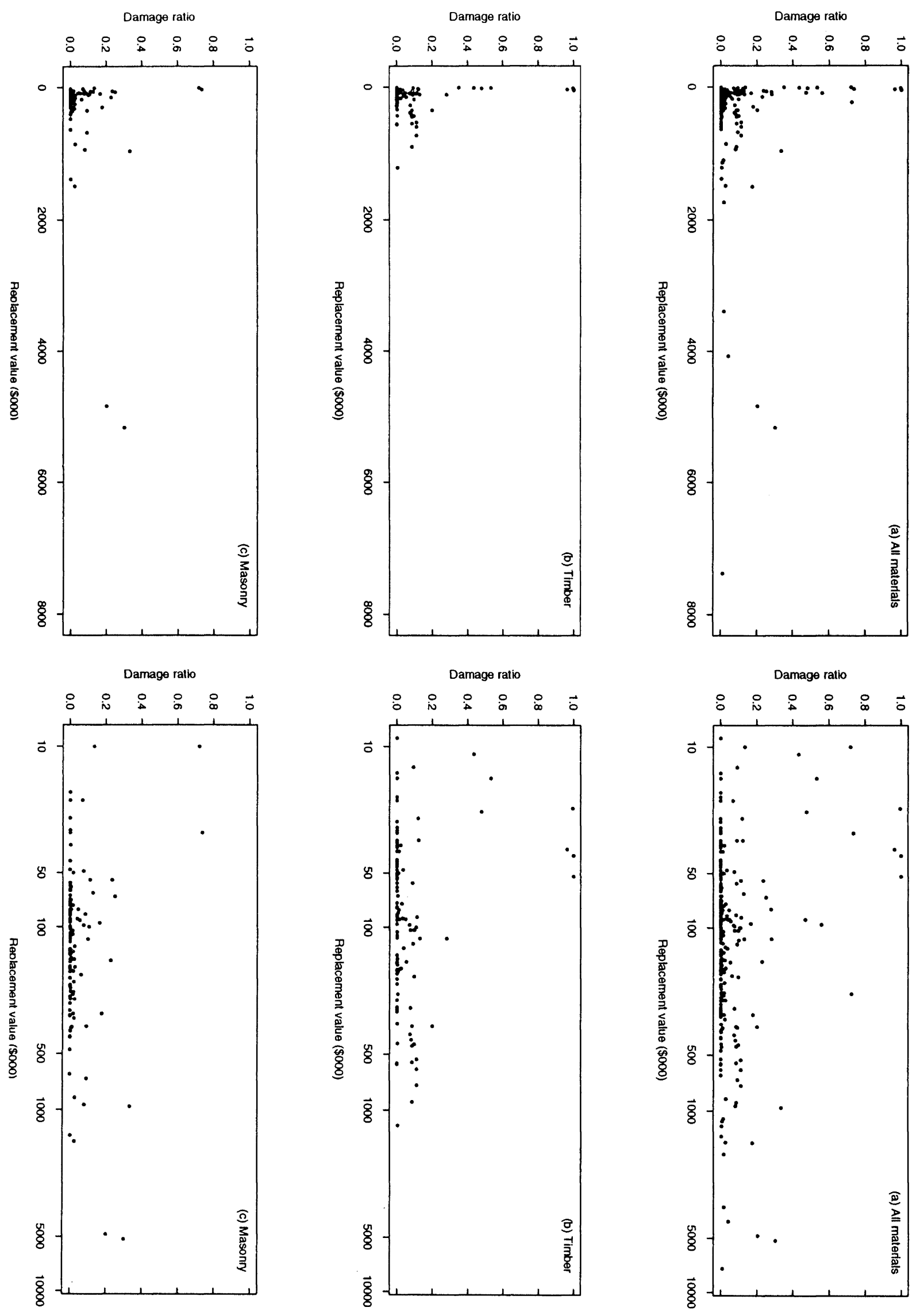

FIGURE 9: $\quad$ Plot of damage ratio versus Replacement Value for one storey non-domestic buildings of design eras (2) and (3), in three subsets: (a) all materials, (b) masonry and (c) timber. 


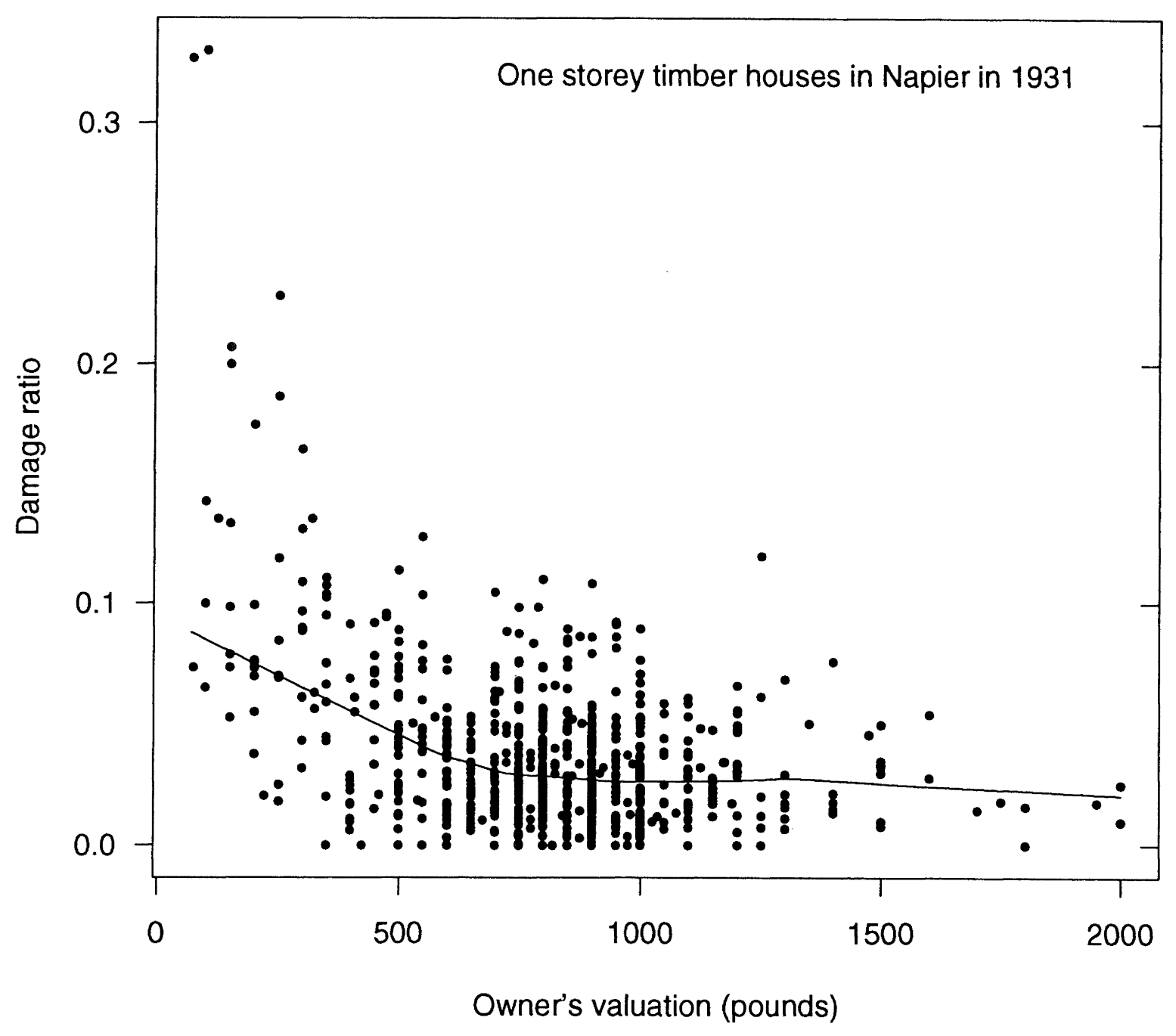

FIGURE 10: $\quad$ Plot of damage ratios versus valuation for one storey timber houses on soft ground in Napier, in the 1931 Hawke's Bay earthquake. A robust fit of the mean damage ratio curve is also plotted. (From Ref. 9)

2. The scatter for all but one of the classes of buildings was greater at intensity MM9 than at MM7, e.g. the standard deviation at intensity MM9 was on average $27 \%$ greater than at MM7. This may be due to nonlinearity of material behaviour being much greater at the higher intensity.

3. None of the 437 non-domestic buildings in the MM9 zone collapsed due to ground shaking, despite several being write-offs, and 324 of them being from the socalled "brittle buildings" era and pre-dating capacity design (i.e. dating from before 1976).

4. Regarding the influence of changes in earthquake resistant design practices in New Zealand, the findings are as follows:

The introduction of the first earthquake design code in 1935 resulted in no significant difference to the vulnerability of one storey timber buildings at intensities up to MM9 inclusive. This result apparently reflects the inherently high earthquake resistance of traditional New Zealand pre-code timber construction, both domestic and non-domestic.

- The introduction of the second earthquake loadings code in 1965 resulted in no significant difference in the vulnerability of non-domestic low-rise buildings for subsets including all materials classes, although there is an apparent decrease in the vulnerability of timber buildings and an increase in the vulnerability of masonry buildings.

- The introduction of improved ductility for concrete in c. 1970 and for other materials in c.1980, resulted in a reduction in the mean damage level at intensity MM9 from that of the previous design era (1935-69/79), i.e.: 

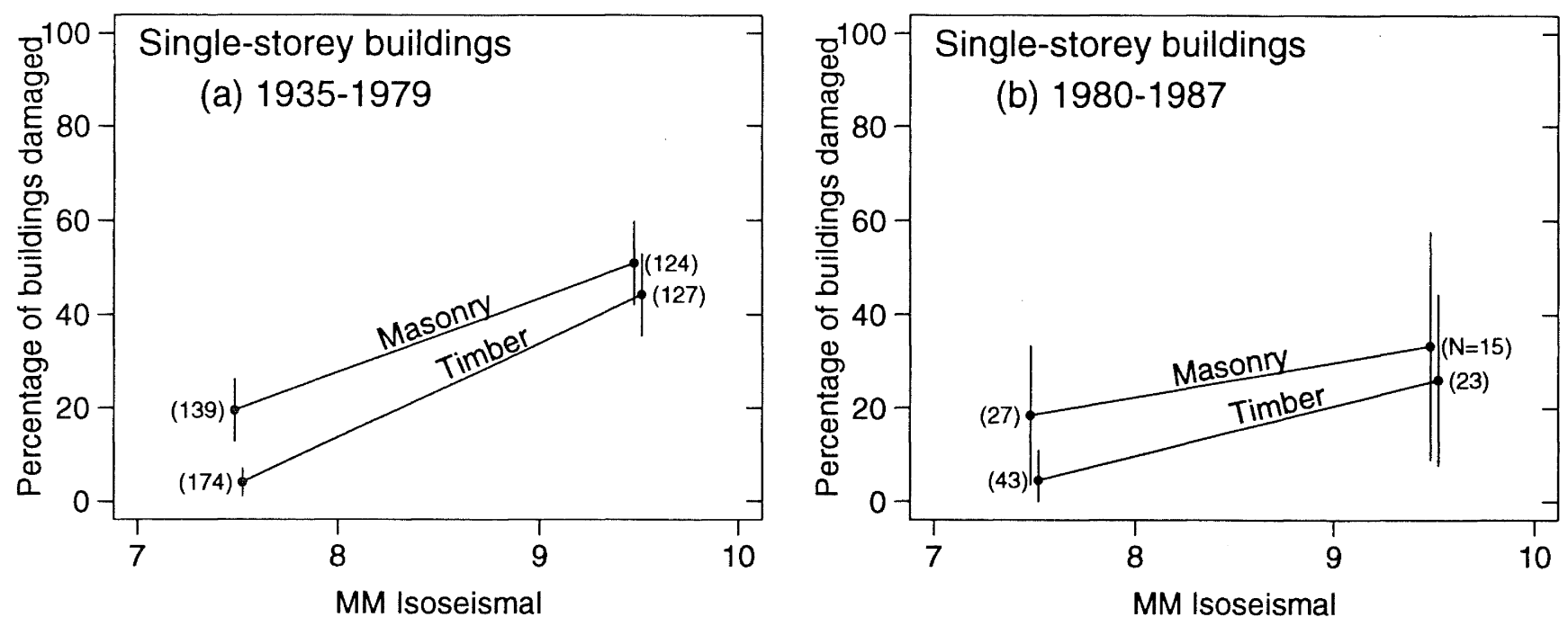

FIGURE 11: Percentages of buildings damaged with their 95\% confidence limits for one storey non-domestic buildings of masonry and timber, from design eras 1935-1979 and 1980-1987, for intensities MM7 and MM9 in the 1987 Edgecumbe earthquake.
All materials (1 storey)
$\mathrm{D}_{\mathrm{rm}}$ fell from 0.059 to $0.016(5 \%)$
Masonry (1 storey)
0.042 to 0.020 (n.s.)
Timber (1 storey)
0.070 to $0.004(1 \%)$
All materials ( 2 storeys) 0.118 to $0.034(5 \%)$

The differences in $D_{m}$ for the two eras were statistically significant at the percentage levels indicated in brackets above; n.s. means not significant.

- Design practice in the most recent era has also resulted in a reduction in heavy damage, the 95th percentile of $D_{r}$ for the intensity MM9 Zone falling from 0.271 (for 1935-69/79) to 0.163 (for $1970 / 80-87$ ), but the difference is statistically insignificant at the 0.05 level.

5. Two storey buildings were found to be significantly more vulnerable than one storey buildings at both intensities MM7 and MM9. This effect may be partly due to the fact that the predominant soil conditions are flexible rather than stiff.

6. At intensity MM9, 1935-1979 one storey timber buildings were significantly more vulnerable than the corresponding masonry buildings. In contrast, for 1980-1987, one storey timber buildings were significantly less vulnerable than the corresponding masonry buildings.

7. At intensity MM9, vulnerability was also found to vary between Use classes, with 1935-69/79 one storey buildings used for industrial purposes being significantly more vulnerable than those used as shops, halls or commercial residences (hotels and motels), probably due to less use of structural walls in industrial buildings.
8. Post-code (1935+) low-rise masonry buildings, as defined in Section 2, afforded good protection against damage at intensity MM9 (New Zealand's highest seismic design zone), even when incorporating unreinforced concrete blocks. The good performance of this class of buildings is attributed to their high ratio of structural wall area to mass.

9. The percentage of buildings, and other classes of property, that are damaged in earthquakes, generally increases with increasing mean damage ratio.

10. Our various studies of damage ratios in this earthquake were feasible only as most of the data on damage costs came from a single source, namely the Earthquake and War Damage Commission (EQC). Hence with the withdrawal of the EQC from the commercial market, it is imperative that insurance companies improve, coordinate and share their post-earthquake data retrieval systems if further valuable insights into the earthquake resistance of non-domestic property are to be obtained from future earthquakes.

\section{ACKNOWLEDGEMENTS}

This study was funded by FRST principally under Contract No. C05405. The authors are grateful to the New Zealand Earthquake and War Damage Commission, who made available their claims files of the Edgecumbe earthquake. Claims data were also provided by the Insurance Council of New Zealand, Commercial Union Insurance, Farmers Mutual Group, New Zealand Insurance and Royal Insurance. Many organisations in the affected area helpfully provided data. We are also grateful to W J Cousins and P N Davenport for their helpful in-house reviews. 


\section{REFERENCES}

Lowry, M.A., Ede, S.C. and Harris, J.S. (1989). Assessment of seismic intensities resulting from the 1987 Edgecumbe earthquake, New Zealand, and implications for modernising the intensity scale, $N Z$ Jnl Geology and Geophysics, 32(1), 145-153

Dowrick, D.J. and Rhoades, D.A. (1990), Damage ratios for domestic buildings in the 1987 Edgecumbe earthquake, Bulletin NZ National Society for Earthquake Eng., 23(2), 137-149.

Dowrick, D.J. (1991), Damage costs for houses and farms as a function of intensity in the 1987 Edgecumbe earthquake, Earthquake eng. struct. dyn., 20, 455-469.

Dowrick, D.J. and Rhoades, D.A. (1993), Damage costs for commercial and industrial property as a function of intensity in the 1987 Edgecumbe earthquake, Earthquake Engineering and Structural Dynamics, 22, 869-884.

Dowrick, D.J. and Rhoades, D.A. (1995), Damage ratios for commercial and industrial equipment and stock in the 1987 Edgecumbe, New Zealand, earthquake, Bulletin NZ National Society for Earthquake Engineering, 28(4), 265-278.

Dowrick, D..J. and Rhoades, D.A. (1997), Inferences for design, insurance and planning from damage in past New Zealand earthquakes, Journal of Earthquake Engineering, 1(1), 77-91.

7. MP 12: 1965, Commentary on Chapter 8 of NZSS 1900, New Zealand Standards Institute, December 1965.

8. Zhao, J.X., Dowrick, D.J. and G.H. McVerry, (1997), Attenuation of peak ground accelerations in New Zealand earthquakes, Bulletin NZ National Society for Earthquake Engineering, 30(2), 133-158.

9. Dowrick, D.J., Rhoades, D.A., Babor, J. and Beetham, R.D. (1995), Damage ratios for houses and microzoning effects in Napier in the magnitude 7.8 1931 Hawke's Bay, New Zealand earthquake, Bulletin NZ National Society for Earthquake Engineering, 28(2), 134-145.

10. Dowrick, D.J., Damage and intensities in the magnitude 7.8 1931 Hawke's Bay, New Zealand, earthquake, (in preparation). 